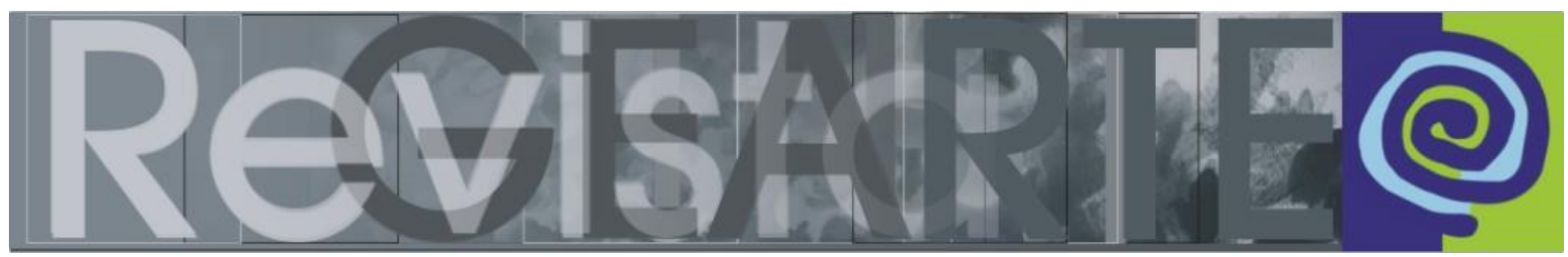

ISSN 2357-9854

\title{
O tempo, o museu e a mediação: o contemporâneo no espaço museológico
}

\author{
Júlia Rocha Pinto (Universidade do Estado de Santa Catarina — UDESC, Florianópolis/SC, Brasil)
}

RESUMO - O tempo, o museu e a mediação: o contemporâneo no espaço museológico - $O$ presente texto problematiza questões próprias da contemporaneidade que balizam as experiências educativas realizadas com os públicos nos museus de artes. Nesse sentindo, buscando compreender como a educação se constrói nas instituições museológicas, hoje, o artigo se centra na análise da transição do museu que atende a preceitos do modernismo e que, gradualmente, passa a incorporar reflexões pertinentes ao tempo contemporâneo. Inseridos e pensados a partir de questões da contemporaneidade, os setores educativos dos museus se vêm desafiados na criação de estratégias de recepção aos públicos que fujam de preceitos modernistas. Como conclusão, questionando as posturas educativas desenvolvidas em relação ao objeto de trabalho, concebe-se a ideia de mediação cultural como resposta aos desafios colocados às instituições museológicas. ${ }^{1}$

PALAVRAS-CHAVE

Mediação Cultural. Contemporaneidade. Museus.

ABSTRACT - The time, the museum and the mediation: the contemporary at the museological space - This paper discusses particular contemporary issues which mark the educational experiences realized with the audiences in art museums. In this sense, trying to understand how education is built in museological institutions today, the article focuses on the analysis of the transition of the museum that meets the precepts of modernism and that gradually begins to incorporate reflections pertinent to contemporary times. Inserted and thought of contemporary issues, the museums's educational sectors are challenged in the creation of strategies of reception to the public that scape from modernist precepts. As a conclusion, questioning the educational postures developed in relation to the museum object, the idea of cultural mediation is conceived as a response to the challenges put to the museological institutions.

\section{KEYWORDS}

Cultural Mediation. Contemporaneity. Museum.

"The discursive change, (...) we might say, one that switches from diachrony to synchrony".

Rosalind Krauss (1990, p. 7)

É com essa frase que Krauss anuncia no texto The Cultural Logic of the Late Capitalist Museum o fim do museu moderno, dizendo que a mudança que demarca essa transição do museu moderno para o contemporâneo é uma substituição da discursividade em torno da História da Arte, quando a diacronia é substituída pela sincronia.

1 Este artigo é parte da tese "Reflexões sobre o meio - O espaço entre a Escola e o Museu de Arte Contemporânea", realizada no Doutoramento em Educação Artística da Universidade do Porto, Portugal e financiada pela CAPES. 
Para Krauss (1990, p. 7) o "museu enciclopédico" tinha a intenção de contar uma história, pensando na visita dos públicos com base em saberes próprios do domínio do museu, que se consolidavam no campo da História da Arte no caso específico dos museus de artes. A autora sinaliza essa mudança de postura, dizendo que o museu passa a ser transformado em nome de uma procura em provocar uma experiência para os visitantes que não se funda neste domínio do tempo cronológico.

Pensando no que é o contemporâneo, Agamben (2009, p. 59) também fala em diacronia, usando o termo "não-coincidência", e refletindo que contemporâneo não é aquele que vive num outro tempo:

Pertence verdadeiramente ao seu tempo, é verdadeiramente
contemporâneo, aquele que não coincide perfeitamente com este, nem está
adequado às suas pretensões e é, portanto, nesse sentido, inatual; mas
exatamente por isso, exatamente através desse deslocamento e desse
anacronismo, ele é capaz, mais do que os outros, de perceber e aprender o
seu tempo.

O que se identifica desse pensamento não é uma negação da história, até porque é incoerente querer desconsiderar esta perspectiva quando os processos históricos são partes constitutivas do que se tem no momento; mas sim compreender que esta transitoriedade de tempos e o entendimento da história é que oferecem a clareza do tempo presente.

A compreensão dos outros tempos, aqui demarcados pela linha da história, permite o entendimento e a presentificação no presente - o tempo do sujeito. Agamben (2009, p. 62-63) afirma que contemporâneo é o sujeito que percebe o seu tempo não na busca pelas luzes, mas na procura do escuro; para o autor "Todos os tempos são, para quem deles experimenta contemporaneidade, obscuros. Contemporâneo é, justamente, aquele que sabe ver essa obscuridade, que é capaz de escrever mergulhado apenas nas trevas do presente".

Dentro dessa perspectiva, a contemporaneidade se propõe como uma relação com o tempo, que busca a sincronia e o distanciamento com o propósito de compreensão deste. A contemporaneidade "[...] é uma singular relação com o próprio tempo, que adere a este e, ao mesmo tempo, dele toma distâncias; mais 
precisamente, essa é a relação com o tempo que a este adere através de uma dissociação e um anacronismo", como refere Agamben (2009, p. 59).

No estar presente dentro do tempo, mas se posicionar fora dele para compreendê-lo, é que se configura o desafio do sujeito contemporâneo, na relação entre proximidade e distanciamento temporal. A percepção do escuro não é realizada numa forma de inércia ou passividade, afirma Agamben (2009, p. 63), mas implica uma atividade e uma habilidade particular em conseguir ver em um tempo o que existe do outro. Este compromisso não tem lugar somente no tempo cronológico porque é nele que algo surge e se transforma.

Para além disso, não é possível associar simplesmente o termo contemporâneo com o tempo presente porque para Agamben (2009, p. 70)

[...] presente não é outra coisa senão a parte de não-vivido em todo vivido, e aquilo que impede o presente é precisamente a massa daquilo que, por alguma razão [...], neste não conseguimos viver. A atenção dirigida a esse não-vivido é a vida do contemporâneo. E ser contemporâneo significa, nesse sentido, voltar a um presente em que jamais estivemos.

O desencontro com o agora, em uma percepção cronológica, é que permite compreender o presente e o tornar contemporâneo,porque contemporâneo não é aquele que identifica a escuridão do presente e o responde com uma determinada luz, mas é aquele que divide e interpela o tempo na tentativa de transformá-lo e colocá-lo em relação a outros tempos, como ainda sugere Agamben (2009, p. 72).

Transpondo esta reflexão em torno do termo contemporâneo e do que ele provoca aos sujeitos do presente para dentro dos museus, talvez seja possível construir um conceito de museu contemporâneo que não necessariamente seja o que trata de objetos produzidos no presente. Nesse sentido, Bishop (2014, p. 6) problematiza como essas instituições se estabelecem no presente, identificando um posicionamento de engajamento em relação ao momento histórico, quando afirma "Today, however, a more radical model of the museum is taking shape: more experimental, less architecturally determined, and offering a more politicized engagement with our historical moment”. 
Repensando esta categoria de contemporaneidade, Bishop (2014, p. 6) apresenta dois modelos diferentes: o primeiro deles compreende a ideia de presente, na condição de tratar do momento atual como o horizonte do pensamento que, de acordo com a autora, é a concepção adotada pela arte hoje, na incapacidade de compreender a constituição da presente época histórica. Nesse sentido, é como se contemporâneo fosse tudo aquilo que não é presente - associação distante do conceito proposto por Agamben.

No segundo modelo, a contemporaneidade é percebida como um método dialético e um projeto político com um entendimento mais radical da temporalidade. É o que Bishop (2014, p. 6) intitula como contemporaneidade dialética: "Time and value turn out to be crucial categories at stake in formulating a notion of what I will call a 'dialetical contemporaneity', because it does not designate a style or period of the works themselves so much as an approach to them".

Umas das consequências desse segundo modelo é a necessidade de se repensar os museus, as categorias de arte e as relações produzidas com os espectadores destas instituições. A indicação de um trabalho que não seja centrada em uma abordagem histórica, que justifique a produção dos objetos museológicos e busque uma relação dialética com outros tempos é a que é proposta como contemporaneidade no contexto tratado neste artigo.

Neste sentido, a história é referida como base da compreensão do tempo que se vive, tal como proposto por Agamben (2009). A constituição dos museus com esta postura contemporânea não recai no relato cronológico de fatos, mas na reflexão constituída a partir dos marcos temporais na determinação do agora. Sobre esse assunto, Belting (2015, p. 21) refere:

The temporality of museums, so distinct from the flux of everyday time, was for a long time tantamount to the history of their collection or to a history that is manifested in their collection. Today, they must rethink their mission when they are expected to represent the rapidly changing world in the mirror of single art works. Their fate is still with their audience whose identity claims have become the main concern in cultural terms. They need the presence of history, to be sure, of history that matters for a local community or a nation. History, however, has to be represented or rediscovered, and sometimes reinvented, as it is threatened by a global traffic of goods and ideas. 
A criação de uma condução das exposições nesta estrutura dos museus, os posiciona em diálogo na sua própria constituição, uma vez que $o$ artefato museal não é entendido descolado do seu tempo e nem mesmo do seu processo histórico. A atitude contemporânea abre para uma meta-museologia, como se, ao mesmo tempo em que se inscreve dentro do espaço do museu identificando interpretações a partir de seus objetos, também existisse para os sujeitos a consciência dos processos que determinam essas interpretações, algo que posteriormente é pensado no processo de mediação.

Buscando exemplificar, Bishop (2014, p. 6) indica três museus que estão descentralizando-se do modelo citado por Krauss como ultrapassado, sendo apresentados como exemplos de realização prática do seu conceito de contemporaneidade dialética. Os três museus são: o Van Abbermuseum, em Eindhoven, Holanda; o Museo Nacional Centro de Arte Reina Sofía, em Madri, Espanha e o Musej Sodobne Ometnosti Metelkova, em Liubliana, Eslovênia.

Para a autora, esses museus estão realizando um trabalho diferenciado em relação à arte e fugindo do movimento dominante presente nessas instituições. Bishop (2014, p. 56) destaca que "These museums create multi-temporal remapping of history and artistic production outside of national and disciplinary frameworks, rather than opting for a global inclusivity that pulls everything into the same narrative". Neste sentido, há um desligamento do tempo corrente dos objetos com as leituras que se fazem deles nos processos curatoriais.

A complexidade aqui trata de diferenciar museus de arte contemporânea de museus com uma postura contemporânea, tendo a ressalva de que essas duas tipologias não precisam ser dissidentes. Manen (2012, p. 12) indica que a arte contemporânea apela para uma postura questionadora, "De todos modos, la exposición de arte contemporáneo trabaja con contenidos que se encuentram en constante modificación y posta en crisis, con lo que las formas aprendidas tocará desprenderlas". Contudo, nem sempre uma postura que incorpora a crise como ferramenta precisa vincular-se à produção artística pós década de 1960 . 
Mais do que se construir ferramentas de análise para o trabalho museológico a partir da arte contemporânea, o que se propõe é pensar como um posicionamento crítico passa a ter espaço dentro dos museus, convocando a construção de novas estruturas. Rice (2002, p. 2) menciona que

In contemporary critical thinking, the museum can no longer claim to be a neutral backdrop for the display of art, because it is understood instead to be a highly complex institution that participates in the social construction of culture and in the legitimization of power.

As estruturas de poder estão presentes nos museus desde a construção de narrativas das exposições até ao trabalho de recepção dos públicos, com a mediação, isto não é negado como existente. Essa postura contemporânea está,contudo, construída a partir de um museu que compreende que não existe neutralidade nos seus discursos e que a complexidade é maior do que explicitamente os objetos com os quais se trata.

Mesmo dentro da produção artística, existem dissidências na terminologia que situa o contemporâneo, porque há um distanciamento maior do que o temporal para determinar o conceito. Não é porque um objeto é produzido neste tempo, situado cronologicamente no hoje, que se enquadra dentro do que se determina e conhece como "arte contemporânea". "The contemporary becomes less a question of periodization of discourse than a method or practice, potentially applicable to all historical periods", como refere Bishop (2014, p. 59).

A este respeito, Bishop (2014, p. 15) menciona uma série de museus que foram sendo renomeados ao longo dos anos e de exemplos como o do Museu de Luxemburgo que se intitulou o "museu dos artistas vivos" em oposição clara ao Louvre, que se dedicava à exposição de obras dos artistas tidos como históricos. A partir de uma necessidade de negar titulações, uma leva de "New museums" foi surgindo no intento de atualizar nomenclaturas que já não correspondiam com o tempo vigente. Mesmo dentro desta provocação, é possível situar museus com foco na produção contemporânea que acabam recorrendo a exposições de artistas modernos, geralmente visando o grande público que uma destas mostras pode trazer ao museu. 
A perspectiva, convém lembrar, não é circunscrever as coleções como eixo da determinação da contemporaneidade, o que se propõe é identificar posicionamentos, escolhas e trabalhos que se aproximem do anacronismo e do deslocamento que são propostos por Agamben (2009) na procura de determinar o que é ser contemporâneo e de que forma isto influencia o que é desenvolvido dentro dos museus.

E mesmo no entendimento do tempo contemporâneo para o campo da museologia existem distinções na determinação de que momento é que se fala. Neste sentido, Bishop (2014, p. 19) propõe que as teorias acerca do contemporâneo se dividam em dois campos: o primeiro deles defende que este é a sequência do pósmodernismo, vindo a substituí-lo depois do seu fim, e o segundo argumenta que o contemporâneo surge em oposição ao pós-modernismo, promovendo uma relação disjuntiva com a temporalidade.

As duas modalidades de contemporâneo são observadas em diferentes exemplos de museus, não se restringindo à oposição binária entre uma ou outra. Ainda remontando a Bishop (2014, p. 23), podemos discutir essa temporalidade ao pensar que mesmo os museus com uma coleção tida como histórica também podem ter uma postura diferente, quando se tornam um campo fértil para realizar um trabalho que se situe no não-presente e multi-temporal eixo da contemporaneidade.

Ainda hoje, quando museus revisitam suas coleções para trabalhar com exposições temporárias que respondam a um determinado tema, existe o exercício em torno deste anacronismo dos objetos, que fazem referência às exposições de média e longa duração, utilizando recursos que ressignificam os objetos num tempo contemporâneo.

Uma concretização dessa ideia acontece no projeto de residência de artistas que a National Gallery de Londres realiza, convidando à produção contemporânea de obras que se baseiam na coleção do museu; abrindo espaço para que os artistas entrem nos arquivos e reservas técnicas da instituição e produzam algo que será exposto nas suas salas. O Museu Victor Meirelles, em Florianópolis, também propunha essa relação, quando convidava artistas contemporâneos para o projeto "Diálogos com a Desterro", em que uma obra era produzida em relação a uma pintura 
do artista brasileiro. Nos dois casos, essas inserções de novos discursos são utilizadas como recurso e convite para que os artistas criem outras entradas para uma obra e, por vezes, atraiam novos públicos ou o retorno dos visitantes.

Contudo, a substituição da narrativa cronológica não é uma garantia de que o museu tome consciência dos discursos que estão expostos, mas é uma possibilidade de recriação dos discursos que até então eram construídos. Com estas proposições, os museus tentam minimamente articular novas correntes de pensamento, tentando escapar da sua condição de depósito de memórias, conceito de Huyssen (1994, p. 37), quando diz que "Fundamentalmente dialético, o museu serve tanto como uma câmara mortuária do passado - com tudo o que acarreta em termos de decadência, erosão e esquecimento - quanto como um lugar de possíveis ressurreições, embora contaminadas e mediadas pelos olhos do espectador".

Por mais salvador que soe o termo "ressureição" citado por Huyssen (1994), o que se propõe é que os objetos expostos dentro dos museus com esta postura contemporânea ganhem novas dimensões que vão além do aspecto expositivo e contemplativo. Por isso, as tentativas de museus históricos de tornar mais atraentes as suas exposições, quando as ressignificam com obras contemporâneas, podem ser um indicativo de uma construção diferente.

O que se identifica aqui é que o questionar-se está no cerne da questão de como os museus podem trabalhar nesta perspectiva contemporânea; se existe uma postura de autorreflexão, é possível estruturar o trabalho mais próximo destas perguntas que movem o novo posicionamento de alguns museus.

Parte das relações de ressignificação das coleções museais pode ser realizada pelas novas estruturas expositivas propostas ou pelo anacronismo dialogado com o convite de artistas que repensem as obras expostas, mas outra possibilidade de pensar esta postura contemporânea pode estar nas propostas educativas feitas com os públicos, nas práticas de mediação cultural. 


\section{O papel educativo: do museu moderno ao museu contemporâneo}

Essas novas posturas presentes nos museus se construíram com base num processo de trabalho que conduziu para as problemáticas presentes na contemporaneidade. As mudanças ocorreram em algumas instituições a respeito das exposições, suas coleções e as formas de expor o acervo. Em paralelo, diferentes posturas educativas são identificadas durante 0 modernismo e 0 tempo contemporâneo, conduzidas ou não pelo tempo em que se situam.

As mudanças de postura em relação aos visitantes e sua participação dentro dos museus estão presentes em contextos diversos, incorporando inquietações da cultura contemporânea e da forma de se relacionar com o conhecimento. Neste sentido, posicionamentos oriundos de bases tradicionais passam a ser ressignificados em trabalhos que pretendem ter uma postura mais crítica em relação aos objetos expostos, bem como para a própria prática. Por isso, propõe-se pensar: como o tempo contemporâneo se faz presente nas propostas educativas dos museus?

Por trabalhar recorrentemente com o público escolar, durante muito tempo, as instituições museológicas se viram reproduzindo saberes e práticas oriundos deste campo, tomando os processos tradicionais de educação em sua prática. Tal como considera Pekarik (2010, p. 109), a tentativa de aproximação das escolas - inclusive justificando o investimento de planos governamentais - levou os museus a serem vistos, no âmbito da educação contemporânea, intimamente ligados aos tipos de resultados que estão associados com a educação regular.

Contudo, as novas correntes educacionais trazidas para o campo dos museus se propõem como um desafio para a participação dos públicos, tal como refere Hooper-Greenhill (2004, p. 572):

The development of new narratives in art museums demands new ways of thinking about collections and audiences, and new ways of integrating the two. The challenges of narrative, voice and difference go to the heart of the power relationships that currently operate in art museums. Finding ways to integrate audience sand their words means finding new ways os balancing power and knowledge. The function of the museum as a communicator cannot be separated from cultural issues of knowledge, power, identity, and language. 
A homogeneização dos processos, das correntes, dos contextos e até mesmo dos públicos marcou este período moderno, quando a criação de um discurso focado em uma verdade era posta em prática, não havendo dentro dos museus a noção das pluralidades postas. Por isso, questiona-se: na construção de um museu detentor de certezas e idealizador de máximas, onde cabia o espaço da dúvida e do posicionamento crítico?

Dentro desse paradigma da modernidade, muitos museus recaem nesta estrutura de relação com os visitantes, desenvolvendo processos de transmissão de conteúdos, porque é assim que perpetuam sua autoridade intelectual. Nesse momento cabe salientar o tempo verbal, quando não se diz que o modelo modernista foi superado e substituído pelo que aqui se nomina como posturas contemporâneas.

Para algumas instituições, as mudanças nas estruturas sociais, na cultura e na identidade pessoal são concomitantes com as mudanças da ordem do controle e das funções que determinam o campo do conhecimento. Hoje os museus são sujeitos a diversas exigências que lhes permitem desempenhar novos papéis, contudo ainda procuram demonstrar sua viabilidade e seu valor em novos contextos onde as verdades não são mais um dado adquirido. De qualquer forma, é necessário considerar que o modernismo construiu um ideal de museu que se distancia em partes do que se percebe das instituições hoje.

O modelo de comunicação adotado no momento de criação dos museus era a transmissão do conhecimento; o museu moderno adotava uma visão lluminista onde o visitante acumulava e absorvia uma gama de informação oferecida com o objetivo de instruir. Reeve e Woollard (2006, p. 5) consideram que, neste contexto, "the relationship could have been considered simple and one-dimensional; the museum was all-powerfull and the uncontested authority".

O sentido da educação realizada dentro dos museus era reduzido a esta relação de recepção da mensagem entendida como verdade acerca do que se visualizava dentro do espaço expositivo. Com esta concepção, o responsável pela comunicação era o educador do museu, aquele que detinha o discurso que deveria 
ser passado sem modificação para o visitante, que recebia passivamente os dados transmitidos. Sobre esta conduta, Hooper-Greenhill (2004, p. 561-2) indica que

The transmission model of communication can be used to explain the moral imperative that underlay much of the use of culture during the 19th century. As museums were established, one of their most prominent functions lay in the field of education. Education was understood as a process of imparting information and, through this, values, such as to constitute the subject as an ideal citizen.

A concepção de educação, além de tratar do conhecimento como único na construção das verdades, também entendia seus visitantes de forma homogênea, uma vez que estes eram sempre definidos como "público geral". A passividade desta compreensão de transmissão de informações tornava o processo muito insípido, negando aproximações ao cotidiano dos visitantes, naturalizando processos como globais e gerais para todos eles, ordenando o pensamento a partir de um paradigma positivista, ignorando os pontos de vista individuais.

A ideia de se criar uma nova forma de atuação passa a ser construída e, diante desta problemática, Acaso (2011, p. 31) lança a questão: “¿cómo cambiar el paradigma modernista en el que la educación se encuentra anclada y conectar con la realidad social posmoderna, transformando el museo de meta en micronarrativa?".

Com a gradual substituição deste modelo modernista de museu e a entrada de novas linhas de pensamento do âmbito da educação passou-se a considerar outros pontos como relevantes para as relações com os visitantes. Os desafios de uma educação em museus a partir de pós-modernismo incluíam sobretudo a voz, a narratividade e a interpretação dos públicos. "In this way the gallery becomes a place where visitors can challenge, question, engage, reflect and embrace uncertainty in order to learn", conforme referem Pringle e DeWitt (2014, p. 10).

O desafio de substituir a autoridade do museu modernista é assumida pela contemporaneidade e a identidade dos visitantes passa a ser foco de análise destes espaços que buscam saber quem são seus públicos e que estratégias são possíveis para atrair cada vez mais pessoas para suas exposições. Essa tentativa é vista com desconfiança por Sternfeld (2010, p. 1) "Moreover, the educational tasks of the museum - we owe these ideas to the reflexive turn of the New Museology - has first 
and foremost been a technique of power, aimed at absorbing and internalizing bourgeois values". Portanto, ao mesmo tempo que se incluem propostas de incentivo a uma participação dos públicos e dinâmicas de escuta e construção de sentido a partir do outro, o poder do discurso continua presente.

Os públicos passam a ser entendidos em sua particularidade e suas intenções passam a ser ouvidas dentro do museu. Um dos desafios do museu contemporâneo é assumir que esta abstrata construção chamada "o público" é na realidade um complexo e multifacetado grupo de indivíduos dispostos a participar do museu em igualdade de posições. Essa participação passa a ser parte deste museu contemporâneo, aberto às construções realizadas a partir dos consumidores da cultura que produz. A particularidade da experiência ser modificada a cada tempo pelos indivíduos que fazem parte de sua comunidade é que o constitui como contemporâneo do tempo em que se inscreve, e não condicionado a uma tipologia defensável de acervo.

Com um crescimento e uma abertura à participação dos públicos, HooperGreenhill (2004, p. 563) refere que um processo de recriação das memórias passa a ser construído e os museus tratam do passado com maior profundidade, tentando abarcar as vozes silenciosas, identidades culturais que foram esquecidas (e ignoradas) no passado. As políticas de construção do poder ainda estão presentes, mas tentando dar espaço para a construção coletiva do conhecimento e o estabelecimento de relações de troca.

O sentido de cultura se modifica de maneira geral e, dentro dos museus, o conceito é entendido como uma construção oriunda de processos de comunicação, onde a identidade individual não pode ser ignorada. Estratégias de interpretação passam a fazer parte do estudo dos museus, que querem atingir seus possíveis visitantes e abrir espaço para que o sentido dos objetos seja criado através das leituras destes, é o que passa a ser entendido como mediação cultural.

As estratégias de trabalho privilegiam processos de construção de sentido, como sugere Hooper-Greenhill (2004, p. 566) quando diz que "The process of constructing meaning from a pairing, for example, is circular and dialogic. We are in a 
question-and-answer mode, a continuous process as the answers build on those questions that have already been asked and answered". Sendo assim, os significados são construídos em processos circulares, com modificações feitas constantemente ao longo do percurso.

As mudanças, de acordo com Brenson (2004, p. 100), tornam os museus menos distantes, menos arrogantes, menos intimidantes e menos seguros, provocando uma modificação na relação dos públicos com as instituições, que passam a fazer parte da rotina cultural dos visitantes. O autor afirma ainda que os museus gostam de usar palavras como hospitalidade, abertura, diálogo, parceria e comunidade para descrever suas identidades, quando afirmam que as exposições são um espaço comum que promove a participação daqueles que as visitam. Contudo, é com grande ressalva que o Brenson (2004, p. 103) aponta estas palavras:

\begin{abstract}
So the transformation of the museum into a hospitable, multipurpose space, not in conflict with but fully integrated into the economic and entertainment fabric of the country, in which more and more people can find meaning in art, needs to be considered with care. These changes are filled with potential. By welcoming and engaging a broader public, museums can become civic spaces with active and influential voices in the perception and formation of culture. But the preoccupation with hospitality, accessibility, and popularity can also lead museums to exploit the public, deceive themselves, betray art, discard the artist, and put the museum in the service of political and economic interests that do not want imaginatively testy art to be shown or the difficulty and edginess of familiar art to surface.
\end{abstract}

Os museus se veem, portanto, nesta tensão entre se abrir ao acesso do público e construir práticas dialogadas e mediadas em oposição com a passividade de se posicionar a serviço de uma função apolítica, porque, vale considerar, não existe educação pautada em uma posição neutra; ela é sempre política.

A intenção de uma postura crítica se concebe na desconstrução da mitificação do museu, questionando o poder dos discursos. Este questionamento é necessário não somente para os públicos, mas também para os educadores dos museus. De acordo com Fróis (2015, p. 66), esta mudança só é possível quando o museu "modifica o modo como os discursos são apresentados, diluindo as suas concepções de autoridade interpretativa e provocando a autonomia entre os seus desígnios e as suas ações com os visitantes". 
Esta autonomia dos visitantes e dos próprios educadores é construída na permissividade do posicionamento crítico e na apropriação das leituras como próprias da sua experiência e do seu repertório. A construção de um processo educativo realizado nos museus dentro do modelo da contemporaneidade busca dar esta autonomia ao visitante, que é impelido a participar dos processos de construção de sentidos. Acaso (2007, p. 75) propõe que "El museo debe desarrollar una pedagogía de la emancipación, como algo que nos permita entender intelectualmente qué somos y lo que hacemos en un orden social determinado". A consciência dos processos permite a crítica que abre espaço para esta autonomia do visitante perante os museus.

Contudo, a emancipação dos visitantes parece ser temida pelas instituições, como se a resposta para esta tomada de consciência fosse a inexistência dos serviços educativos. Isto pode até acontecer, mas a instrumentalização de uma relação que fuja da passividade não desvincula a criação de propostas de mediação e desenvolvimento de estratégias educativas dentro dos museus; o que se enfrenta é o desafio de que estas instituições sejam espaços reflexivos e abertos a outras possibilidades de trabalho que não incorporem saberes próprios da escola dentro de um espaço que se distingue como tal.

\section{Conclusões}

Diante desta nova constituição dos papéis que os museus podem desempenhar, passa-se a compreender que os serviços educativos não precisam atuar como defensores da existência destas instituições - prática ainda bastante recorrente por parte das equipes atuantes. A postura da mediação cultural é até mesmo uma resposta das mudanças ocorridas por parte dos próprios museus, pois como sugere Padró (2009, p. 55) "Se o museu considera-se um centro de desconstrução, de suposições ou controvérsias, a educação contribuirá para apresentar o museu como um lugar em contínua construção".

Dessa maneira, os museus são espaços propícios para a elaboração de propostas que convoquem os sujeitos como participantes ativos dos seus próprios processos. As visitas realizadas não precisam ser conclusivas, geradoras de respostas ou momentos para a concretização de uma aprendizagem, as práticas de 
mediação cultural são mais espaços para trocas que propõem uma visão crítica perante o objeto museal e que possivelmente construam novos discursos a partir das narrativas já presentes no museu.

A postura contemporânea pensada para as instituições museológicas pode se concretizar, portanto, na mediação cultural realizada com seus públicos, visto que na abertura ao diálogo os museus permitem leituras críticas e posicionamentos que remetem aos preceitos do sujeito contemporâneo pensados no início deste texto. Dando possibilidade à autonomia dos visitantes frente às interpretações criadas nas exposições, os museus constituem-se como espaços educativos abertos ao conceito de contemporaneidade dialética proposto por Bishop.

O entendimento de que a mediação cultural se apresenta aqui como uma abordagem metodológica que detém este posicionamento do tempo contemporâneo, permite compreender que as práticas não estão restritas ao conteúdo exposto nos museus. A abordagem pode estar presente em instituições com múltiplas perspectivas e frentes de trabalho, mas sempre pensando em espaços museais que atendam a estas questões postas para a nominada "postura contemporânea".

\section{Referências}

ACASO, María. ¿Por qué a la educación artística no le gustan los museos? Repensando los problemas actuales de la educación artística en las instituciones culturales. In: CALAF MASACHS, Roser; FONTAL MERILLAS, Olaia; VALLE FLÓREZ, Rosa Eva (Orgs.). Museos de arte y educación: construir patrimonios desde la diversidad. Gijón: Ediciones Trea, 2007.

ACASO, María. De la invisibilidad al giro educativo. In: ACASO, María (Org.). Perspectivas: situación actual de la educación en los museos de artes visuales. Madrid: Fundación Telefónica, 2011.

AGAMBEN, Giorgio. O que é o contemporâneo. Chapecó: Argos, 2009.

BELTING, Hans. Contemporary art as global art: a critical estimate, 2015. Disponível em: <http://www.globalartmuseum.de/media/file/476716148442.pdf>. Acesso em: 21 mai. 2015.

BISHOP, Claire. Radical museology: or what's "contemporary" in museums of contemporary art? Londres: Koenig Books, 2014.

BRENSON, Michael. Acts of engagement: writings on art, criticism and institutions, 1993-2002. Oxford: Rowman \& Littlefield Publishers, 2004.

FRÓIS, João Pedro. Os museus de arte e a educação: discursos e práticas contemporâneas. Disponível em: http://repositorio.ul.pt/handle/10451/2353. Acesso em: 19 fev. 2015.

HOOPER-GREENHILL, Eilean. Changing values in the art museum: rethinking communication and learning. In: CARBONELL, Bettina Messias (Org.). Museum studies: an anthology of contexts. Londres: Blackwell Publishing, 2004. 
HUYSSEN, Andreas. Escapando da amnésia: o museu como cultura de massa. Revista do Patrimônio Histórico e Artístico Nacional, v. 23, p. 35-57, 1994.

KRAUSS, Rosalind. The cultural logic of the late capitalist museum. The MIT Press, v. 54, p. 3-17, 1990.

MANEN, Martí. Salir de la exposición (si es que alguna vez habíamos entrado). Bilbao: Consonni, 2012.

PEKARIK, Andrew. From knowing to not knowing: moving beyond "outcomes". Curator: The Museum Journal, v. 53, n. 1, p. 105-115, 2010.

PRINGLE, Emily; DEWITT, Jennifer. Perceptions, processes and practices around learning in an art gallery. Tate Papers, n. 22, s. p., Autumn 2014. Disponível em: $<\mathrm{http}: / /$ www.tate.org.uk/research/publications/tate-papers/perceptions-processes-and-practicesaround-learning-art-gallery>. Acesso em: 10 fev. 2015.

REEVE, John. Influences on museum practice. In: LANG, Caroline; REEVE, John; WOOLARD, Vicky (Orgs.). The responsive museum: working with audiences in the twenty-first century. Burlington, VT: Ashgate, 2006.

RICE, Danielle; YENAWINE, Philip. A conversation on object-centered learning in art museums. Curator: The Museum Journal, v. 45, n. 4, p. 289-301, 2002.

STERNFELD, Nira. Unglamorous tasks: what can education learn from its political traditions? E-flux Journal, v. 14, p. 1-12, March, 2010.

\section{Júlia Rocha Pinto}

Doutora em Educação Artística pela Universidade do Porto. Mestre em Artes e Educação pela Universidade Estadual Paulista. Licenciada em Artes Plásticas pela Universidade do Estado de Santa Catarina. Professora no Centro de Artes da Universidade do Estado de Santa Catarina (UDESC).

E-mail: juliarochapinto@gmail.com

Currículo: http://lattes.cnpq.br/1973788294795614 